\title{
Geometria e Estrutura A Arquitectura das Moléculas: de Buckminister Fuller aos Fullerenos ${ }^{1}$
}

\author{
JORGE C.G. CA LA D O *
}

\section{INTRODUÇÃO}

Arte e ciência influenciam-se mutuamente e fazem-no, em geral, através dum intermediário - a $\mathrm{Na}$ tureza. Foi Bronowski ${ }^{1}$ que disse que, para o homem comum, a chave da ciência se encontra na sua unidade com as artes. Por outras palavras, o entendimento da ciência é enormemente facilitado pela análise dos seus múltiplos paralelos com as artes. Inversamente, o conhecimento científico mostra-se essencial para a apreciação da arte moderna, principalmente a mais abstracta e esotérica. Há atrasos e adiantamentos inevitáveis nas respostas de uma às solicitações das outras, mas em geral as artes e as ciências seguem as mesmas modas e reflectem o 'Zeitgeist' que acompanha o progresso humano. A descoberta da estrutura de novas formas de carbono chamadas fullerenos, que este ano deu o Prémio Nobel da Química a Harold Kroto, Richard Smalley e Robert Curl ilustra bem esta íntima dependência entre a ciência e a arte.

O percurso de qualquer processo criativo ou imaginativo é feito de associações e estas passam, em geral, pelo reconhecimento de estruturas, nomeadamente formas geométricas. Não admira, pois, que nos confins do racionalismo as teorias mais universais fossem construídas com base nas formas mais simples, facilmente identificáveis. Formas que, como a circunferência, eram consideradas inevitáveis e naturais, no sentido pitagórico e aristotélico. Um quadrado ou um círculo, uma vez vistos ou concebidos mentalmente, são dificilmente esquecíveis; pelo contrário, uma linha quebrada complicada ou uma curva que se enrodilha são difíceis de reproduzir. (Alguns testes de aptidão e exercícios de memória são baseados nestes factos). A estrutura da água ou a do sal das cozinhas fazem parte do inconsciente colectivo duma pessoa medianamente culta; a dum polímero é bem mais difícil de entrar no repertório corrente.

A molécula da água define um plano; a ordem do cristal é tridimensional (simetria translaccional). Há um enorme salto qualitativo entre as duas estruturas, tanto mais que a visualização no espaço a três dimensões constitui, para os adultos, uma grande barreira psicológica. A verdade é que, embora tenhamos a experiência da vida num mundo a três dimensões, ficámos com o vício das duas dimensões e tudo o que involve a imaginação da terceira requer um treino especial. A nossa visão e experiência da Terra é a duas dimensões. (Mesmo quando voamos de avião, a subida em altitude é desprezável em relação à distância percorrida). A leitura e a escrita processa-se em folhas que são espaços a duas dimensões. A aprendizagem faz-se com quadros, transparências, slides, etc que continuam essa planaridade. A criança, pelo contrário, tem uma percepção muito mais directa e profunda da tridimensionalidade, até porque ela própria é comensurável com os objectos que a rodeiam. Aos olhos da criança (que é como quem diz, ao seu cérebro) o mobiliário é enorme; os cubos e os elementos do Lego com que brinca são do tamanho das suas mãos. A criança cresce num mundo que é o de Gulliver no país de Brobdingnag. É este tambem o mundo fotografado pelo pequeno Lartigue (1894-1986), um fotógrafo genial cuja carreira se iniciou aos 8 anos de idade. Essa percepção perdese quando se começa a ler, e a planaridade do papel oblitera a terceira dimensão.

\section{OS SÓLIDOS PLATÓNICOS}

Sabe-se que os Gregos reduziram o comportamento da natureza à existência dos quatro elementos $\mathrm{e}$ às suas interaç̧ões, e que imediatamente associaram estes elementos a quatro dos sólidos platónicos - os poliedros regulares de faces idênticas (triângulos, quadrados, pentágonos). O tetraedro bicudo e móvel representava o fogo, o cubo inerte e bem assente no plano a
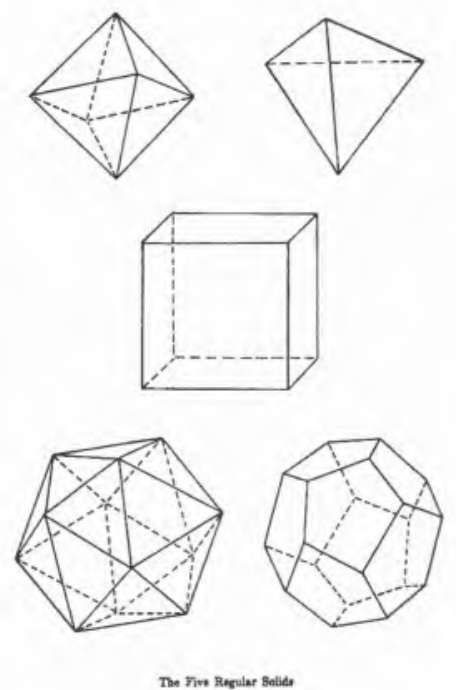

Fig. 1 - Poliedros regulares

terra, o octaedro rolante o ar e o icosaedro a água - Figura 1.

$\mathrm{O}$ quinto sólido platónico, o dodecaedro (o único cujas faces são pentágonos) correspondia à substância dos corpos celestes. Muitas das teorias cosmológicas, incluindo as de Kepler (1571-1630) recorriam a relações entre os sólidos regulares. A ideia de Kepler foi passar da aritmética para a geometria. Em vez de basear a organização do universo, nomeadamente os raios das órbitas dos planetas, numa relação de números como queriam os pitagóricos, Kepler utilizou diagramas geométricos. Primeiro lançou mão dos polígonos regulares que inscreveu e circunscreveu em circunferências, e depois usou as esferas e os cinco sólidos regulares - Figura 2.

Kepler não esqueceu a música e, recorrendo às relações pitagóricas entre os comprimentos das cordas e os sons por estas produzidos, representou ainda o movimento dos planetas nas suas órbitas por um grupo de notas musicais - a harmonia das esferas. O novo sistema, divulgado no seu Mysterium Cosmographicum publicado em 1596 quando tinha 25 anos de idade, era notoriamente mais simples do que o velho sistema ptolomaico, mas não convenceu Tycho Brahe (1546-1601) que o aconselhou: "Primeiro tenta es- 


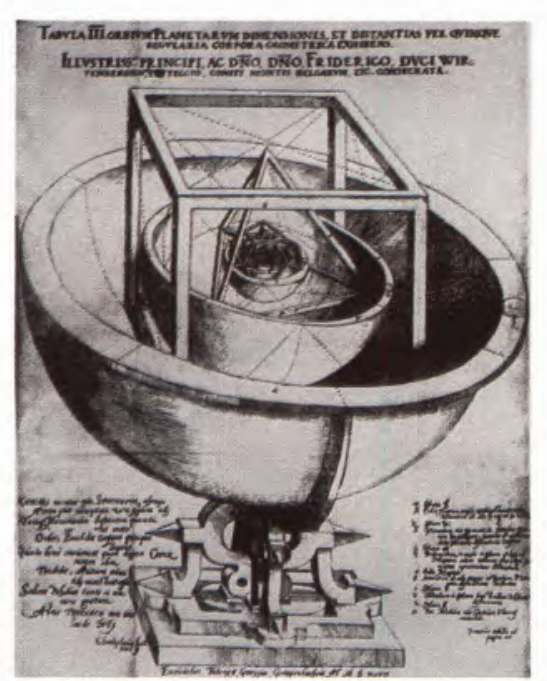

Fig. 2 - Frontispício de Mysterium cosmographicum (1596) de Kepler

tabelecer uma fundação sólida para as tuas opiniões através da observação e depois, apoiado nesta, tenta alcançar as causas das coisas". No entanto, Brahe convidou Kepler para seu assistente no Observatório Real em Praga e, após a sua morte, Kepler sucedeulhe no lugar de astrónomo da corte do Imperador Rudolf II.

Os sólidos regulares (e suas variantes) desempenharam um papel importantíssimo nas ligações renascentistas entre arte e ciência. O ma-

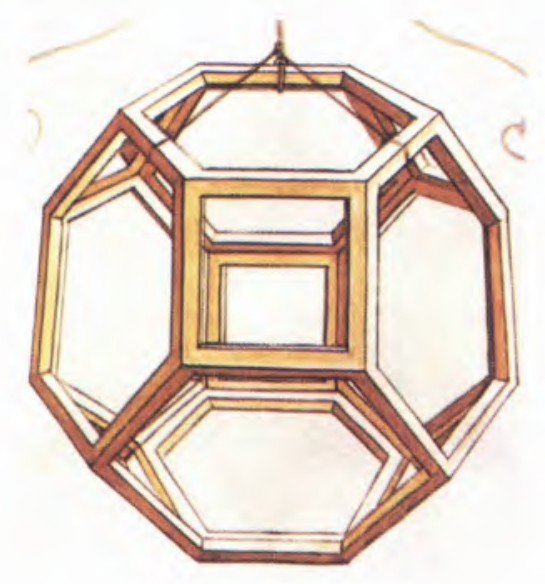

Fig. 3 - LEONARDO, Desenho de Corpos Geométricos para De divina proportione, de Frei Luca Pacioli temático franciscano Frei Luca Pacioli não só se inspirou nos trabalhos do pintor Piero della Francesca (c. 1420-1492), como até convenceu Leonardo da Vinci (1452-1519) a ilustrar o seu tratado De divina proportione (1509). Alguns dos sólidos derivados, nomeadamente as formas esteladas, constituiam verdadeiros desafios à perspectiva representacional. Os desenhos de Leonardo - Figura 3 - são um exemplo, raro na época, de grande clareza exemplificativa, e Pacioli não se coibiu de lhes chamar "figuras extraordinárias e muito belas".

Num quadro atribuido a Jacopo de' Barbari (1494?), o frade matemático aparece a consultar os Elementos de Euclides, e entre os acessórios distingue-se o dodecaedro sólido (à direita, em cima de uma das suas obras) mais um poliedro semiregular - o rombicuboctaedro transparente e suspenso por um fio,

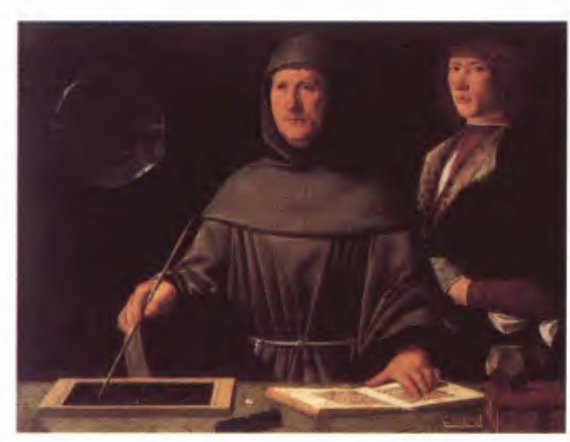

Fig. 4 - JACOPO DE' BARBARI (?), Retrato de Frei Luca Pacioli com um Jovem cavalheiro (1494?)

à esquerda - Figura 4. Sabe-se que Pacioli foi dos primeiros a construir e a usar sistematicamente modelos dos solidos geométricos.

A truncagem dos vértices dos poliedros regulares dá origem a uma nova série de poliedros. Essa truncagem pode ser feita de maneira a que todas as faces resultantes sejam polígonos regulares, mas coexistindo mais do que uma espécie de polígonos; todos os vértices repousam então na esfera circunscrita. A estes poliedros dá-se o nome de poliedros semi-regulares ou de Arquimedes. De particular importância é o icosaedro truncado que exibe pentágonos e hexágonos; este poliedro tem ao todo 32 faces e 60 vértices e cada vértice é a intersecção de dois hexágonos e um pentágono. O resultado é uma bola de futebol - Figura 5:

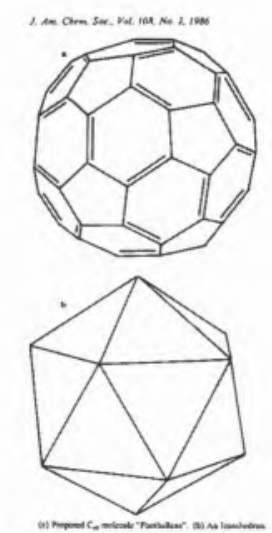

Fig. 5 - Icosaedro Truncado

É de salientar a importante presença do pentágono, o polígono que contem a raiz da misteriosa secção áurea (relação entre a diagonal do pentágono e o respectivo lado). Tal não acontece nem com o triângulo, nem com o quadrado, nem com o hexágono. Por outras palavras, os pentágonos são potencialmente mais belos que os outros poligonos regulares. Não é por acaso que o homem de Vitrúvio, recuperado por Leonardo, define uma estrela de cinco pontas (cabeça, mãos e pés) inscrita num círculo.

\section{O HOMEM E A NATUREZA}

A importância das formas regulares não é menos visível na arte. Cézanne (1839-1906) falava em reduzir tudo às formas elementares do cubo, cone e cilindro que são, aliás, vislumbráveis em muitas das suas paisagens e naturezas mortas. É nesta visão que estão as raizes de toda a pintura moderna. O cubismo de Braque (1882-1963) e Picasso (1881-1973) tambem recuperou a dignidade da linha recta e do polígo- 
no em pintura, e o vorticismo, carregado de energia, de Wyndham Lewis (1884-1957) e A. L. Coburn (18821966), fez o mesmo em relação à pirâmide e ao cone.

A verdade é que as formas naturais e inevitáveis dos Gregos estão omnipresentes nas nossas construções mentais. O cientista serve-se delas para elaborar teorias ou imaginar estruturas, o arquitecto usa-as como critérios estéticos e de funcionalidade, o pintor encontra-as subjacentes à variedade da natureza. São elas que estão na base da unidade profunda entre as obras da natureza (mineral, vegetal e animal) e as obras do homem. Leonardo da Vinci (1452-1519) viu o corpo humano como uma suprema obra de engenharia e adoptou algumas das suas características à solução de questões complexas de mecânica e hidráulica. Aliás as soluções tecnológicas que o homem e a natureza encontraram para a solução dos seus problemas são, muitas vezes, as mesmas. São, em geral, razões económicas, que todos entendem e que na física são chamadas leis de conservação (ou leis de menor esforço), que explicam esta unidade. As gotas são esféricas: a menor área para o mesmo volume (minimização da energia de superfície). Os favos de mel têm estrutura hexagonal: minimização da área lateral dum sistema contínuo de células. Esta unidade entre a obra do homem e a obra da natureza - que a engenharia é una - atingiu o apogeu na era da máquina. Foi o período dos anos 1920-30's, uma era optimista de progresso e de bem-estar. A velocidade estava na ordem do dia, e tudo - do automóvel ao aspirador, do comboio ao ferro de engomar - era aerodinâmico. Foi uma estética a que o fotógrafo Albert Renger-Pätzsch (18971966) deu forma com a publicação do livro Die Welt ist Schön (1928), do qual se extraiu a fotografia da Figura 6 - uma disposição quase cubista e cinemática de panelas.

A ideia é olhar para as formas independentemente do conteúdo ou

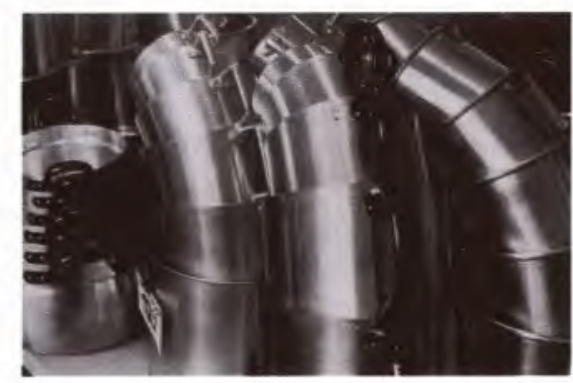

Fig. 6 - RENGER-PÄTZSCH, Panelas

do seu valor utilitário, isto é, fazê-lo com a frescura com que Marcel Duchamp (1887-1968) exibiu o seu urinol invertido chamando-lhe Fonte (1917). Foi isto, precisamente, que Roald Hoffmann (Prémio Nobel da Química, 1981) recentemente e neste mesmo lugar (IST) pediu, ou melhor, exigiu dos químicos: a capacidade para olhar para as coisas, mesmo as mais familiares, com olhos novos, certo de que assim se descobrem outros significados e possibilidades que são sempre novas estruturas no sentido real ou metafórico. Como exemplo ${ }^{2}$, o carboneto de escândio $\mathrm{Sc}_{3} \mathrm{C}_{4}$ de estrutura tetragonal, cuja cela unitária pode ser vista de três belas maneiras, todas elas fazendo sentido: (i) assinalando as várias espécies de carbono $\mathrm{C}, \mathrm{C}_{2}$ e $\mathrm{C}_{3}$;

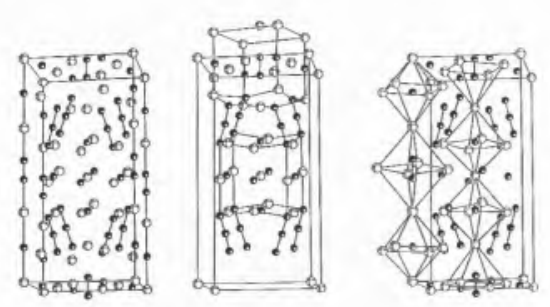

Fig. 7 - Estrutura do $\mathrm{Sc}_{3} \mathrm{C}_{4}$

(ii) definindo estruturas do tipo do $\mathrm{NaCl}$ ligadas por unidades $\mathrm{C}_{3}$ no plano (001) e (iii) com unidades octaédricas $\mathrm{Sc}_{6}$ - partilhando os vértices ao longo da direcção [001] (ver Figura 7).

\section{ARQUITECTURAS}

$\mathrm{Na}$ arquitectura e artes decorativas as fases de complicação delirante alternaram sempre com os períodos em que o rigor puritano obrigava a um regresso às formas básicas. Houve os excessos do barroco, mas tambem a disciplina regrada do classicismo. A fachada do Teatro de D. Maria II, em Lisboa, em oposição à da Estação do Rossio. No século XVIII Boullée (1728-1799) e Ledoux (1736-1806) foram arquitectos revolucionários e visionários e não apenas porque viveram no tempo da Revolução e a maior parte das suas obras ficou por construir. De certo modo eles respondiam ao anseio romântico de criar uma "architecture parlante", de fazer o edifício falar não através da decoração mas da sua forma global. A linguagem encontrada era, uma vez mais, a da geometria elementar, baseada em formas simples como o cubo, o cilindro, a pirâmide e principalmente a esfera. (As ligações desta arquitectura com o credo maçónico não foram ainda suficientemente exploradas). O resultado era uma arquitectura nova para uma nova ordem social. A esfera é a menos tectónica de todas as formas e por isso alguns viram nesta obcessão dos arquitectos com a esfera um sintoma ou metáfora da instabilidade revolucionária. Mas é impossível não ficar empolgado com a sublime imponência de projectos como o do Cenotáfio de Newton (1784) de Boullée, uma enorme esfera vazia e constelada . Figura 8.

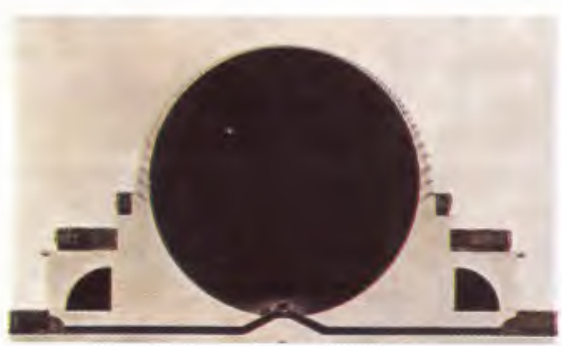

Fig. 8 - BOULLÉE, Cenotáfio de Newton 
Boullée envolveu Newton com a sua própria descoberta, homem e obra unidos para além da morte, que a esfera é símbolo de eternidade. Como ele afirma em Architecture Essai sur l'Art, "c'était dans le séjour de l'immortalité, c'otait dans le ciel que je voulais placer Newton". A esfera é também uma forma única, padrão do individualismo e célula de retiro; apropriada portanto para guardar a memória dos grandes. A esfera pode não ser hoje a mais popular das formas arquitectónicas, mas tem contribuído para a solução de alguns complicados problemas de engenharia. Veja-se o que aconteceu com a Sydney Opera House, emblema arquitrectónico desse outro período visionário e revolucionário que foram os anos 60 (inaugurada em 1973). As magníficas conchas cupulares da obra de Ultzon foram decalcadas dum conjunto de gomos esféricos ${ }^{3}$ - Figura 9.
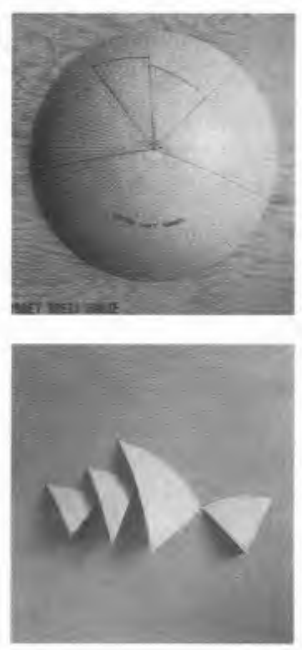

Fig. 9 - Esfera e Gomos

A obra foi renegada por Utzon, mas em Dezembro de 1991 foi eleita pelos leitores do Sunday Times (Londres) como a maravilha número um do mundo contemporâneo.

\section{ARQUITECTURA MOLECULAR}

Ao químico interessa sobremaneira a arquitectura das moléculas, mas o que se passa neste mundo não é muito diferente da arquitectura construida à face da Terra. Sabe-se como foram enormes saltos de progresso - aquilo que os anglosaxónicos chamam erroneamente "quantum leaps' - os conceitos de elemento, de equivalente, de valência ( $\mathrm{em}$ particular a tetravalência tetraédrica do carbono devida a van't Hoff (1852-1911)). O inventor dos modelos atómicos foi um antigo estudante de arquitectura, virado para a Química pelas aulas inspiradoras de Liebig (1803-1873). Estou-me a referir, evidentemente, a Kékulé (18291896). A ele se devem as ideias da formação de longas cadeias de átomos de carbono (que, segundo reza a lenda, the ocorreu durante um devaneio ao passear de autocarro em Londres em 1854 ou 1855) ou mesmo a criação de estruturas cíclicas como a do benzeno, que lhe deu a imortalidade. Deve referir-se, todavia, que Loschmidt (1821-1895) foi muito provavelmente o primeiro a postular a estrutura hexagonal do benzeno (1861).

O hexágono benzoico esteve na base da criação da indústria química e tornou-se a figura emblemática da química moderna. Ele é, também, uma forma perfeita. A ubiquidade do átomo de carbono justificou toda uma química - a orgânica. Só o silício, elemento do mesmo grupo IV A, se lhe aproxima. Na forma elementar havia os tetraedros do diamante e as camadas hexagonais da grafite, embora mais tarde se viessem a descobrir novas formas de carbono (incluindo novas formas de diamante e grafite). A estrutura da grafite normal está representada na Figura 10.

Hoje, na era dos "computer graphics" e quejandos, estas representações parecem ingénuas, mas à data do seu aparecimento 4 foram saudadas como um marco importante do realismo químico, uma espécie de descoberta fotográfica. Foi com estes diagramas de estruturas moleculares que Pauling levou os adolescentes de todo o mundo a acreditar que os átomos eram mesmo esféricos. Em 1964 Pauling colaborou com um arquitecto e ilustrador, Roger Hayward, para

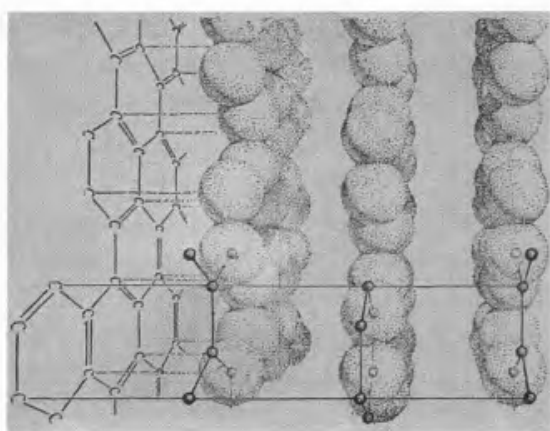

Fig. 10 - Estrutura da Grafite

produzir um belo livro5 - The Architecture of Molecules - que foi saudado pela crítica como uma obraprima da edição científica. Aí se encontra uma variedade de estruturas moleculares, desde as mais simples (halogéneos, por exemplo) às mais complexas (seda, virus do polioma). É desse livro que se extrai o aspecto dum cristal de diamante visto por um 'observador' muito pequeno, com a altura equivalente ao diâmetro dum átomo de carbono - Figura 11.

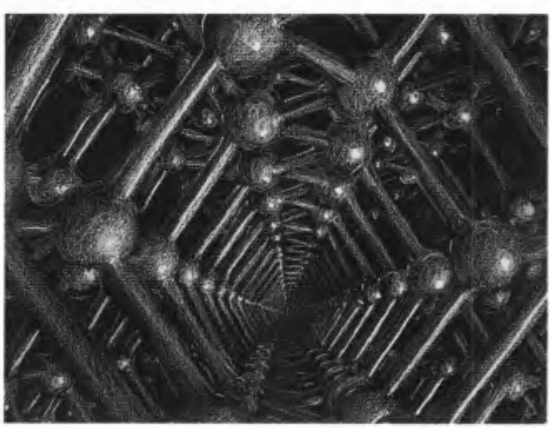

Fig. 11 - Vista dum cristal de diamante

A evolução da representação das fórmulas e estruturas químicas ao longo dos tempos era um assunto para outro artigo. Tal como na pintura, passou-se do concreto para o abstracto.

Boullée e companheiros não hesitariam em usar as estruturas maravilhosas da química para construir os seus monumentos às glórias da ciência e dos cientistas. As cúpulas e esferas não abundam, mas existem os clatratos em cujo interior repousam os hóspedes moleculares. E o respectivo espectro de vibração é, à escala 
microscópica, uma espécie de música das esferas. Na Figura 12 mostra-se um dos tipos de clatratos da água (hidratos), com o seu empilhamento de dodecaedros e hexadecaedros, isto é, pentágonos e hexágonos.

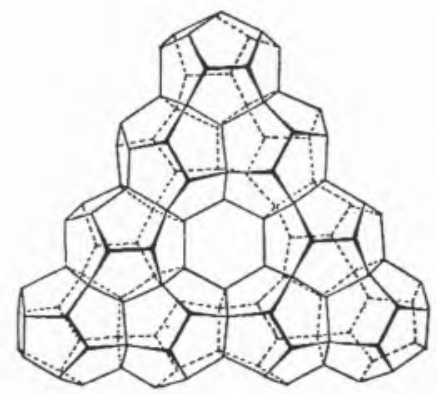

Fig. 12 - Empilhamento de Dodecaedros e Hexadecaedros em Hidratos do Tipo II

\section{ENTRA BUCKMINSTER FULLER}

O nosso século produziu tambem um construtor visionário - Richard Buckminster Fuller (18951983). Sem curso universitário (frequentou a universidade de Harvard mas não se formou), Fuller atribuiu toda a sua formação técnica à passagem pela marinha americana durante e após a I Grande Guerra. Aos 32 anos, e sem dinheiro, resolveu embarcar num projecto aparentemente lunático a que dedicaria os restantes 56 anos de vida: investigar6 "como e porque é que os humanos estão aqui a bordo desta nave esférica a que chamamos Terra $[. .$.$] ; meditar sobre os recursos fisi-$ cos totais que descobrimos a bordo do nosso navio e ver como usar o conhecimento cumulativo total para que este navio funcione para todos". O objectivo último era, também na sua linguagem muito especial, "a auto-integração espontânea e omni-fisicamente bem sucedida de toda a humanidade ... num mundo de uma só cidade". Aquilo que muito mais tarde outros chamariam a "aldeia global". Foi um percurso que o levou a criar um carro revolucionário chamado Dymaxion (Dynamic + Maximum + Ions) e a aplicar as suas teorias ao design de casas prè-fabricadas.
A ideia era produzir, com novos materiais, estruturas extremamente leves e resistentes, facilmente transportáveis. Os seus projectos e invenções têm algo da originalidade e simplicidade das propostas de Leonardo cerca de 500 anos antes. As teorias em que se baseava eram, na melhor das hipóteses, esotéricas (o tetraedro como modelo geométrico dum pensamento, por exemplo), mas os resultados funcionavam. Apesar do ridículo com que foram recebidos muitos dos seus projectos e patentes, Fuller acabou a vida cumulado de honrarias e com um reconhecimento quase geral. A sua especialidade eram as cúpulas geodésicas, que podiam funcionar como habitação, abrigo ou hangar. Explorou-as em todas as suas variedades estruturais e deixou mais de 300000 espalhadas por todo o mundo. Como ele gostava de salientar, as duas cúpulas maiores do mundo estão em Roma (São Pedro e o Panteão), medem aproximadamente 50 metros de diâmetro e pesam cerca de 15000 toneladas; pelo contrário, a sua primeira cúpula de 50 metros pesava apenas 15 toneladas e resistia a todas as intempéries, inclu-

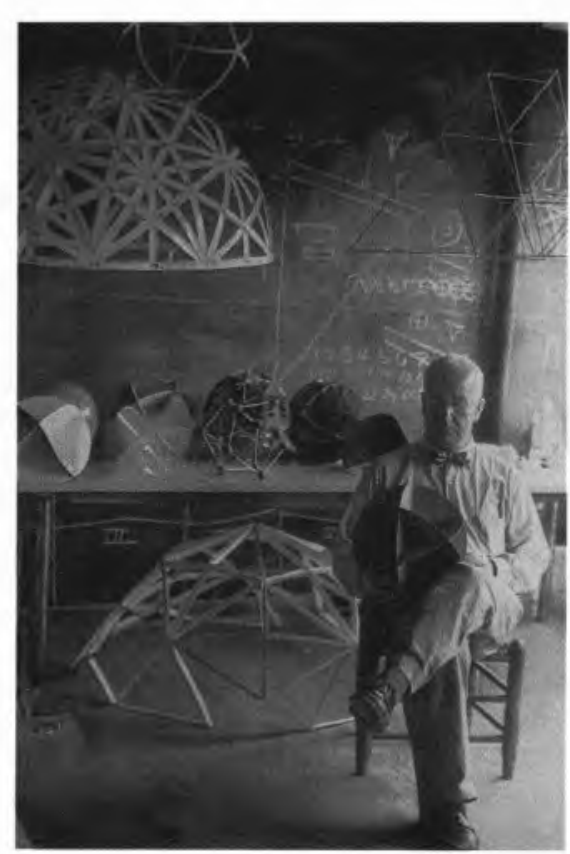

Fig. 13 - Buckminster Fuller no Black Mountain College, 1949 indo os terramotos. A Figura 13 mostra Buckminster Fuller no seu estúdio em Black Mountain College (North Carolina, USA) no Verão de 1949; ao fundo vê-se o modelo para uma cúpula construido com fitas de persiana.

Uma nota passageira: embora tenha durado apenas 24 anos (19331957), o Black Mountain College desempenhou um papel importantíssimo na vanguarda americana ${ }^{7}$. Por lá passaram como mestres e alunos, Gropius, Jung, Kline, Albers, Cunningham, Agnes de Mille, Cage, de Kooning, Motherwell, Rauschenberg, Arthur Penn, Callahan, Newhall, Kenneth Snelson, etc!

Buckminster Fuller concebeu, projectou, construiu ou patenteou milhares de estruturas, em particular cúpulas geodésicas. Entre outras devem referir-se o MonoHex (1965), também chamada Cúpula do Olho de Mosca, formada de pentágonos e hexágonos, e que está indicada na Figura 14, e o Hexa-Pent (1974), onde também combinava hexágonos com pentágonos, feita de contraplacado de madeira, e que destinava a abrigo dos esquimós.

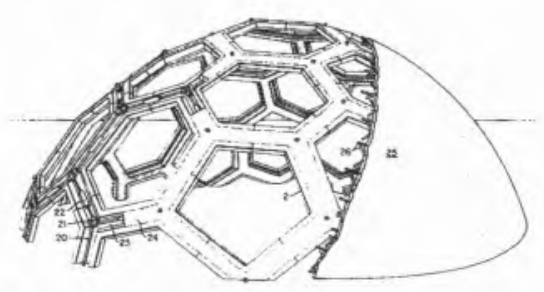

Fig. 14 - MonoHex, 1965

Uma das suas obras-primas foi o Pavilhão Americano na EXPO $67 \mathrm{em}$ Montreal, cuja estrutura ainda hoje pode ser admirada - Figura 15

\section{UMA HISTÓRIA BONITA}

Buckminster Fuller desenhava estruturas como os químicos desenham e fabricam (isto é, sintetizam) moléculas. Era portanto inevitável que o mundo da química e o mundo exótico de Buckminster Fuller se encontrassem, nem que fosse para 


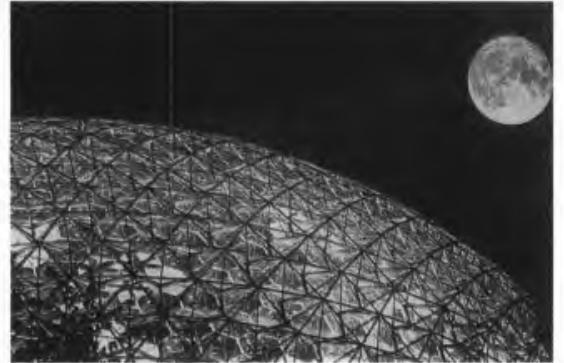

Fig. 15 - Pavilhão Americano, EXPO 67

além da morte. Esse encontro é a história da descoberta da belíssima estrutura duma nova forma de carbono, o $\mathrm{C}_{60}$. A história tem sido várias vezes contada pelos seus protagonistas $^{8}$ - os Nobel da Química deste ano - nomeadamente pelo Professor Harold Kroto quando esteve em Portugal em 1992, a convite da Sociedade Portuguesa de Química9 . Mas é uma história tão bonita que vale a pena lembrá-la.

Mencionei há pouco a ubiquidade do carbono e a sua capacidade para formar cadeias. Um dos assuntos mais excitantes na década de 70 em radioastronomia fora a descoberta, no espaço interestelar, de moléculas com longas cadeias serpenteantes de carbono, como $\mathrm{HC}_{5} \mathrm{~N}, \mathrm{HC}_{7} \mathrm{~N}$, $\mathrm{HC}_{9} \mathrm{~N}$ - os chamados cianopoliinos. Julgava-se que tais moléculas eram produzidas na atmosfera exterior das Estrelas Gigantes Vermelhas, ricas em carbono. Com vista a esclarecer os mecanismos da sua formação, Harold Kroto, professor da Universidade de Sussex em Inglaterra e especialista em espectroscopia de microondas, resolveu em 1985 ir até Houston para utilizar o 'laser-supersonic cluster beam apparatus' (LSCB), desenvolvido na Rice University pelo grupo do Professor Richard Smalley. O princípio de funcionamento é simples: um laser intenso e rápido, capaz de gerar temperaturas da ordem das dezenas de milhar de graus (da ordem das temperaturas das estrelas) impinge na superfície da amostra a estudar, vaporiza-a, e os fragmentos são depois analisados por espectrometria de massa.

No entanto, um ano antes, e utilizando uma das máquinas de
Smalley, um grupo de investigadores da Exxon em Annandale, New Jersey (Eric Rohlfing, Donald Cox e Andrew Kaldor) tinha já investigado feixes supersónicos de cachos ("clusters") de átomos de carbono e verificado que sim, que se formavam cadeias lineares de carbono indo até às dezenas de átomos, e favorecendo, para $n>40$, os números pares. $\mathrm{O}$ artigo 9 mostrava o resultado extraordinário (mas não assinalado!) duma preferência para a formação dos cachos $\mathrm{C}_{60}$ e, em menor grau, de $\mathrm{C}_{70}$ Figura 16

Mesmo assim, e tendo o cuidado de evitar duplicações ou pisar o terreno alheio, Kroto, Smalley e os seus colaboradores (entre os quais Robert Curl, especialista em espectroscopia de cachos ou 'cluster chemistry', também da Rice University) resolveram iniciar os trabalhos. $\mathrm{O}$ vapor de grafite produzido pelo laser era arrefecido por uma corrente

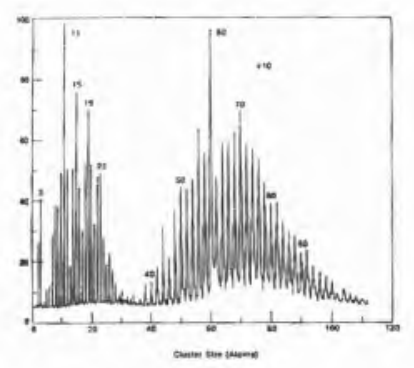

Fig. 16 - Espectro PI-TOF-MS de 'clusters' de carbono

quase supersónica de hélio que provocava a formação de cachos; o hélio era depois expandido numa câmara de vácuo provocando novas reacções, e os produtos analisados por espectrometria de massa. Confirmou-se a formação de longas cadeias de átomos de carbono e a prevalência de cachos de número par elevado entre os quais o de $\mathrm{C}_{60}$ parecia assumir uma importância especial, sendo em geral três vezes mais abundante do que qualquer dos outros. Ajuste das condições experimentais levou a uma intensificação de cerca de 40 vezes! Devia pois haver algo de extraordinário em relação a este cacho com o número mágico 60 .
As primeiras hipóteses apontavam para uma estrutura do tipo sanduiche (tão ao gosto dos químicos organometálicos), tornada possível pela ligação das pontas de valência soltas da malha de grafite - uma espécie de sanduiche feita de fatias de rede de capoeira. Mas ficava por explicar a singularidade do número 60 , e o facto do cacho respectivo ser extraordinariamente estável. Pensou-se então numa estrutura fechada, e vieram à baila as cúpulas geodésicas de Buckminster Fuller. O próprio Kroto tinha em tempos construído uma armação destas no seu quintal para os filhos brincarem, talvez porque se extasiara ao visitar o Pavilhão Americano de Buckminster Fuller em Montreal. Smalley requisitou na biblioteca da universidade um exemplar dum livro sobre a obra de Fuller11, e puseram mãos à obra. Kroto devorou o livro em busca de inspiração, Smalley procurou gerar estruturas geodésicas no computador, enquanto em casa um dos estudantes perdia a paciência com as tentativas infrutíferas de formar uma estrutura decente com 60 pastilhas elásticas (os átomos de carbono) e umas caixas de palitos (a fazer as ligações). Kroto ainda pensou telefonar à mulher em Inglaterra para ela ir desencantar ao sótão os restos da casa abobadada que ele tinha construido para os filhos no jardim, mas não se atreveu a acordá-la às tantas da manhã! Em desespero de causa (Kroto regressava a Inglaterra daí a dias) Smalley tentou o velho método do papel, recortando pacientemente hexágonos regulares, depois também alguns pentágonos, e tentando ligálos uns aos outros com fita-cola até formar uma estrutura fechada com 60 vértices. Escusado será dizer que desta vez o conseguiu, obtendo um bonito poliedro esferóide de doze pentágonos e vinte hexágonos, com os vértices todos equivalentes (resultando sempre da confluência de dois hexágonos e um pentágono). Sem o saber, Smalley tinha recreado um dos sólidos semi-regulares de Arquimedes: o icosaedro truncado. O poliedro de papel caiu ao chão, rolou e 
saltou como uma bola de futebol. Era demasiado giro para não ser verdade! Depois foi a vez de Curl e Kroto tentarem colocar na estrutura, com a ajuda de etiquetas de papel adesivo, as duplas ligações. Há 12 500 maneiras de o fazer, de modo que não lhes foi difícil de encontrar uma - Figura 5.

Em homenagem ao seu inspirador, a molécula foi baptizada com o nome de Buckminsterfullereno ou 'Bucky Ball' para os amigos. (Notar que 'buck' é o calão para dólar, ou 'massa'; os parceiros americanos também sugeriram o nome futeboleno - até carbosoccer! - mas a seriedade britânica de Kroto impediu tais galhofeiras). Quando os resultados 12 foram comunicados à Nature, fizeram inevitavelmente a capa da revista Figura 17

O mais extraordinário nesta história é o facto da proposta ser uma mera especulação. Não havia ainda prova científica da estrutura, mas a ideia era tão bonita que a Nature aceitou publicar a 'Letter'. É um dos raros casos da ciência contemporânea em que um critério estético foi usado como argumento de verdade científica. Belo e verdadeiro são as duas facetas da mesma questão, e a arte é apenas ciência por outros meios. Ou, como o físico Weisskopf observou, arte e ciência são complementares, no sentido proposto por Bohr.

Mais tarde, Kroto, Smalley, Curl e outros puderam confirmar, nomeadamente por RMN, a estrutura do $\mathrm{C}_{60}$. O buckminsterfullereno, sendo o mais estável (mais esférico, com menos tensões) não é o único destes compostos geodésicos. Para o $\mathrm{C}_{70}$, também relativamente abundante, foi proposta a estrutura duma bola de rugby - é um ovoide, um $\mathrm{C}_{60}$ alongado por uma cintura de hexágonos. Constituem uma nova família de compostos relativamente inertes, genericamente chamados fullerenos. Admitem um hóspede no seu interior (à semelhança dos clatratos) e quando atacados por um laser perdem sucessivamente dois carbonos, passando de
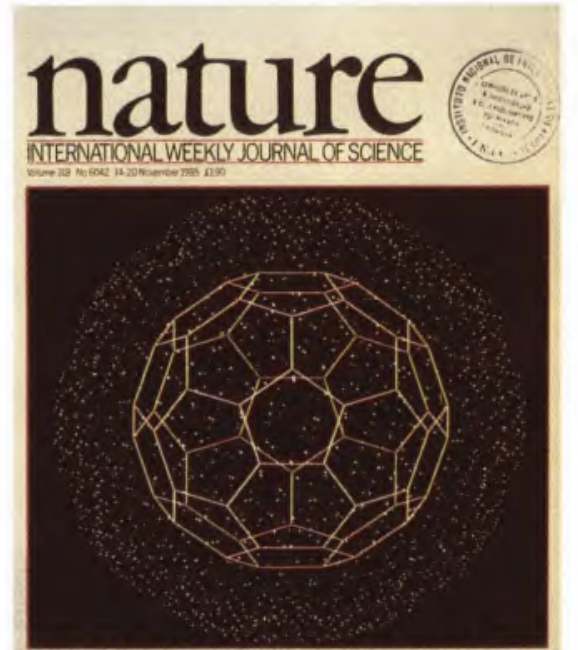

SIXTY-CARBON CLUSTER

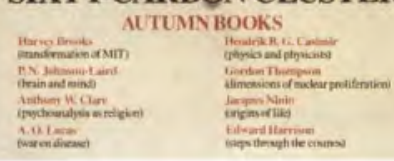

Fig. 17 - Nature, 14 de Novembro de 1985

degrau em degrau aos fullerenos inferiores. O limite é o $\mathrm{C}_{32}$ cujas tensões de curvatura são tão grandes que provocam o rebentamento do esferóide. Daí para baixo predominam as cadeias lineares.

Os fullerenos são produzidos em chamas de queima e são relativamente abundantes na fuligem. Em 1990 Krätschmer e Huffman ${ }^{13}$ criaram um processo eficiente de produção de quantidades significativas de $\mathrm{C}_{60}$ fazendo saltar um arco entre dois eléctrodos de grafite em atmosfera de hélio, e extraindo o produto formado com um solvente orgânico; a solução em benzeno é vermelha. Por maioria de razão, os fullerenos devem estar presentes nas estrelas ricas em carbono, como as Gigantes Vermelhas. Como tal, devem ser das moléculas mais antigas que existem e devido à sua inércia química (explicada pela elevada simetria) e mobilidade, possivelmente as únicas capazes de atravessar o espaço interestelar. Que só agora tenham sido descobertas e estudadas, é uma daquelas ironias de que a ciência está cheia. Como sempre, as ideias mais simples são as mais difíceis de imaginar.
Uma química nova desponta, bela e, a seu tempo, útil e capaz de afectar toda a gente. É certo que as aplicações tardam a vir, mas ainda é cedo para deixar o acaso funcionar (a boa ciência é imprevisível). Os artistas começam a inspirar-se e a entusiasmar-se. A verdade é que a química é poesia feita molécula, poesia realizada no laboratório, no computador ou na mente secreta e solitária do artista que é o químico.

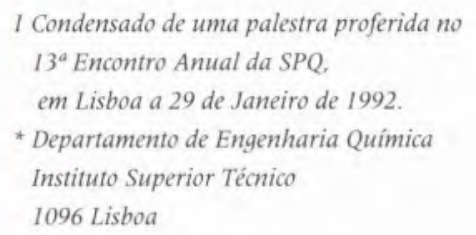

\section{REFERÊNCIAS}

1. J. Bronowski, The Common Sense of Science, Heinemann, London, (1951).

2. H.-Jürgen Meyer, R. Hoffmann, "The Electronic Structure of Two Novel Carbides, $\mathrm{Ca}_{3} \mathrm{Cl}_{2} \mathrm{C}_{3}$ and $\mathrm{Sc}_{3} \mathrm{C}_{4}$. Containing $\mathrm{C}_{3}$ Units".

3. Derek Walker, Great Engineers, Academy Editions, London, (1987).

4. L. Pauling, General Chemistry, W. H. Freeman, San Francisco, (1947).

5. L. Pauling e R. Hayward, The Architecture of Molecules, W. H. Freeman, San Francisco, (1964).

6. Inventions - The Patented Works of R. Buckminster Fuller, St. Martin's Press, New York, (1983).

7. Mary Emma Harris, The Arts at Black Mountain College, MIT Press, (1988).

8. R. E. Smalley, "Great Balls of Carbon - The Story of Buckminsterfullerene", The Sciences (March/April 1991) 22-28,

9. H. Kroto, " $\mathrm{C}_{60}$ : Buckminsterfulereno, a esfera caída dos céus", Colóquio/Ciências №15 (Setembro 1994) 3-16.

10. E. A. Rohlfing, D. M. Cox e A. Kaldo, J. Chem Phys. 81 (1984) 3322-3330.

11. R. Buckminster Fuller e Robert Marks, The Dymaxion World of Buckminster Fuller, Southern Illinois University Press, Carbondale, (1960).

12. H. W. Kroto, I. R. Heath, S. C. O'Brien, R. F. Curl e R. E, Smalley, "C $\mathrm{C}_{60}$ : Buckminsterfullerene", Nature $\mathbf{3 1 8}$ (1985) 162-3.

13. W. Krătschmer, L. D. Lamb, K. Fostiropoulos e D. R. Huffman, "Solid $\mathrm{C}_{60}$. a new form of carbon". Nature 347 (1990) 354 